\title{
Biodegradation of Cypermethrin by pseudomonas in a batch activated sludge process
}

\author{
${ }^{1 *}$ S. Jilani and ${ }^{2} M$. Altaf Khan \\ ${ }^{1}$ Environmental Engineering Department, NED University of Engineering and Technology, Karachi, Pakistan \\ ${ }^{2}$ Institute of Environmental Studies, University of Karachi, Karachi, Pakistan \\ Received 24 May 2006; revised 15 August 2006; accepted 3 September 2006; available online 1 October 2006
}

\begin{abstract}
The biodegradation of Cypermethrin $(20$ to $125 \mathrm{mg} / \mathrm{L})$ in an effluent using batch activated sludge was studied. Degradation was found to occur to a great extent only in the presence of Pseudomonas (IES-Ps-1) culture. Under aerobic conditions using mechanical aerators, Cypermethrin $(20 \mathrm{mg} / \mathrm{L})$ was almost completely degraded in just over $48 \mathrm{~h}$ at ambient temperature. Further loading of organic compound in subsequent experiments demonstrated that IES-PS-1was capable to degrade $82 \%$ Cypermethrin at $40 \mathrm{mg} / \mathrm{L}$ dose in approximately $48 \mathrm{~h}$. When the concentration was increased to $80 \mathrm{mg} / \mathrm{L}, 50 \%$ degradation of this compound was observed. Over this time period the cells could utilize only $17 \%$ of Cypermethrin when it was given $125 \mathrm{mg} / \mathrm{L}$, respectively. These findings indicate that increased concentration of Cypermethrin has a marked effect on biodegradation performance of IES-PS-1 with a modest increased in the duration of lag phase, but did not lead to complete inhibition or cell death. These results proved that IES-Ps-1 is responsible for Cypermethrin degradation. Such finding may be useful in designing a scale-up in situ or on-site hazardous waste bioremediation process for field application.
\end{abstract}

Key words: Cypermethrin, biodegradation, effluent, pseudomonas, mechanical aerators, activated sludge

\section{INTRODUCTION}

Acurrent environmental concern is the contamination of aquatic ecosystem due to pesticide discharges from manufacturing plant, agricultural runoff, leaching, accidental spills and other sources. An effective pesticide waste treatment technology are needed to prevent water pollution and to comply with increasing regulatory pressures. Many approaches to pesticide waste treatment have been considered by the researchers (Yu, 2002; Huston and Pignatello, 1999; Arnol, et al., 1995; Somich, et al., 1990), but few, if any, are sufficiently broad-based and convenient to the user. In view of this, bioremediation i.e. biological method has proven to be a suitable method for the treatment of pesticidespolluted aquifers that could be implemented either in situ or off-site in especially designed reactor or wastewater treatment plants (Tartakouvsky, et al., 2001; Sayler and Blackburn 1989; Kumaran and Shivaraman 1988; Grady 1986). Moreover, in most cases it is most cost effective and environmentally friendly treatment method. Engineers have considered bioremediation using bioreactor, soilbed or land farming techniques

\footnotetext{
*Corresponding author, Email: seemajilani2000@yahoo.com
} Tel.: +92-21 9261261-8; Fax: +92-21 9261255 with indigenous or engineered cultures, a suitable method for the treatment of hazardous waste or polluted aquifers (Mangat and Elefsiniotis 1999; Rozkov, et al., 1999; Roy, et al., 1997; Sisodia, et al., 1996; Zacharias 1995). It is reported that microbial consortia may metabolize a particular compound as a single source of carbon and energy (Karpouzas, et al., 2000; Smith and Adkins 1996; Dolfing, et al., 1990; Haugland, et al., 1990). More recently much effort has been devoted to isolate organism that can degrade not only simpler compound like benzene, phenol, naphthalene, salicylate, toluene, hydroxybenzoates, phenoxyacetates, atrazine etc. but also the complex ones like biphenyls, polychlorinated biphenyle (PCB's), dichlorodiphenyl trichloro ethane (DDT) and hexachloro cyclo hexane (HCH) (Lal, et al., 1995; Straube, 1991; Safe, 1984). Among the different genera of bacteria degrading pesticides, the genus pseudomonas has a special status, as strain of pseudomonas species are known to metabolize a broad range of organic compounds and therefore an ideal choice as the bacteria to be used for degradative biotechnologies. They have, infact, an extraordinary range of catabolic pathways, a single 
species such as P. cepacia utilizes more than 100 different substrates as the only carbon, nitrogen or sulfur source (Dagley, 1986). According to literature, the activated sludge was found to be very effective in the treatment of wastewater containing high concentration of toxic organic compounds but the problem which is being faced by the environmental engineers is the difficulty in predicting the performance of such system with respect to high load of individual organic compounds. A particular difficulty in industrial wastewater treatment plants is the batch nature of many discharges. This has led to difficulty in predicting effluent concentrations by traditional models. Unfortunately very little information is available concerning the effect of varying influent concentration on the rate of biodegradation when toxic compounds like Cypermethrin is present in the treatment system. The research aim was to identify the potential microbial strain able to eliminate Cypermethrin from the effluents. In addition, the optimum dose and the suitable conditions for Cypermethrin degradation using laboratory scale activated sludge was also evaluated. The results of the present study suggest that the use of potential microorganism in the treatment system can successfully overcome many of the disadvantages associated with the conventional batch culture bioreactor used for the degradation of inhibitory compound.

\section{MATERIALS AND METHODS}

Pesticide and chemicals used

Cypermethrin (analytical grade, $96 \%$ pure) was obtained from Pakistan Agriculture Research Council (PARC). Whereas, commercial grade Cypermethrin was purchased from agricultural chemical dealer and used in the experimental research studies. Solvents (n-hexane and methanol) were HPLC grade and other chemicals used were all reagent-grade.

\section{Preparation of culture medium}

Nutrient broth and nutrient agar media (Acumedia) was prepared according to the manufacturer's instruction and was used for growth kinetic studies.

\section{Isolation and maintenance of bacterial culture}

The bacterial culture capable of degrading malathion was isolated by Hashmi (2000) from agricultural soil using enrichment technique, with varying concentrations of malathion in the medium. Wet unsieved soil (2-5 g) from an agricultural site was inoculated into $250 \mathrm{~mL}$ of wastewater in $500 \mathrm{~mL}$ Erlenmeyer flasks containing 10-35 mg/L malathion. The flasks were incubated in a shaking water bath operating at 240 cycles per minute for five days at room temperature (ranged from $20-28^{\circ} \mathrm{C}$ ). At daily intervals one loop full of enrichment culture from the flasks was streaked on nutrient agar plates supplemented with malathion $(5.7 \mathrm{mg} / \mathrm{L})$ and incubated at $35^{\circ} \mathrm{C}$ for $24-48$ h. Individual colonies were subcultured into nutrient agar plates containing same concentration of malathion until pure culture was isolated.

The IES-Ps- 1 strain was maintained at $4{ }^{\circ} \mathrm{C}$ and subcultured after every three months. When a new batch of test was performed with different dose and type of pesticide, the stock culture was first subcultured into $10 \mathrm{~mL}$ nutrient broth, aerobically grown and subsequently utilized for characterization, growth and biodegradation studies.

\section{Identification and characterization of IES-Ps-1}

The identification and characterization of the IESPs-1 was performed using morphological, cultural and biochemical tests as described by Colins and Lyne (1985) up to the stage of genus.

\section{Enumeration of viable cell count}

The IES-PS-1 was enumerated with and without adding pesticide. Aliquot $(2.5 \mathrm{~mL})$ of $24 \mathrm{~h}$ culture grown in nutrient broth was inoculated into $25 \mathrm{~mL}$ nutrient broth flask containing different concentration of Cypermethrin and tested their ability to degrade supplemental substrate (the pesticide). Control flasks of equal volume of nutrient broth medium containing culture but no pesticide were run in parallel to confirm that significant die off was not occurring over the period of each test. Three replicate were performed for each dose of Cypermethrin for a total of 12 tests, including the zero dose (control).

\section{Growth kinetic studies}

Growth of the isolate was determined by viable cell enumeration immediately after inocculation and at 2, 4, 6 and 24 h later. Miles and Misra technique was used for bacterial growth study. Sample of bacterial culture $(1 \mathrm{~mL})$ was drawn at regular intervals and serial dilutions $\left(10^{-5}-10^{-8}\right)$ of bacterial culture with and without addition of pesticide (control) was performed using $9 \mathrm{~mL}$ sterile saline blank (0.85\% NaCl; $\mathrm{pH}=7)$. Appropriate dilutions 
of bacterial samples were plated in triplicate on nutrient agar medium. Each plate divided into four segments and used for several dilutions. Three drops of culture were placed in each section of nutrient agar plate and were allowed to dry followed by incubation at $35^{\circ} \mathrm{C}$ for $24 \mathrm{~h}$. After incubation the viable colonies were counted using the method described by Collins and Lynes (1985) and results were reported accordingly.

\section{Cypermethrin degradation studies}

The ability of IES-Ps-1 for Cypermethrin degradation was determined using a shaking water bath and biosimulator (activated sludge system).

\section{Cypermethrin degradation studies in shaking water bath}

Duplicate flasks of $500 \mathrm{~mL}$ capacity, each containing $250 \mathrm{~mL}$ of wastewater sample and Cypermethrin was prepared (40 mg/L). One flask was inoculated with 25 $\mathrm{mL}$ of bacterial culture while the other flask was only amended without adding bacterial culture to assess the degradation potential of IES-Ps-1. Both the flasks were placed in a shaking water bath at ambient temperature $\left(25^{\circ} \mathrm{C}\right)$ for $24 \mathrm{~h}$. Disappearance of Cypermethrin from wastewater was checked by withdrawing samples from both flasks after 8 and $24 \mathrm{~h}$ incubation period and processed for HPLC and other analysis. All tests were performed in triplicate.

\section{Cypermethrin degradation studies in biosimulator (activated sludge system)}

The compact bench scale biosimulator (Model MF114) consists of a stainless steel reactor with a heavy wall glass jar of borosilicate glass equipped for monitoring and controlling rate of agitation and aeration was used. The effect of different concentrations of Cypermethrin $(40 \mathrm{mg} / \mathrm{L}, 80 \mathrm{mg} / \mathrm{L}$ and $125 \mathrm{mg} / \mathrm{L}$ ) on the performance of IES-Ps-1 for biodegradation was evaluated. Approximately 8.5 liters wastewater sample, inoculated with $350 \mathrm{~mL}$ culture and added with appropriate quantity of Cypermethrin was transferred into the biosimulator. The sample was strongly agitated by impeller with flat stirring paddles and by four vertical baffles. The concentration of dissolved oxygen (DO) as mg/L was achieved by mechanical aeration regulated through continuous agitation. Agitation was continuously monitored on a calibrated electrical tachometer, which provided accurate speed indication.

\section{Analytical procedure}

The samples from shaking water bath were withdrawn at 0,8 and $24 \mathrm{~h}$ whereas from biosimulator at timed intervals of $8,24,32,48 \mathrm{~h}$ and analyzed for $\mathrm{pH}$, temperature, dissolved oxygen and COD as per standard procedure laid down in APHA (1992).

\section{Extraction of Cypermethrin for HPLC analysis}

Samples were collected from shaking water bath and biosimulator as per schedule and were extracted two times with n-hexane ( $75 \mathrm{~mL}$ and $50 \mathrm{~mL}$ ) by vigorous shaking for 15-20 min in a separatory funnel. The hexane layer was separated and evaporated to dryness at 70 ${ }^{\circ} \mathrm{C}$ using vacuum rotary evaporator (BUCHI Rotavapor $\mathrm{R}-200 / 205)$. The dried residue was then dissolved in $10 \mathrm{~mL}$ HPLC grade methanol. After gently vortexing and filtering through a $0.2 \mathrm{~mm}$ membrane filter, an aliquot of $20 \mathrm{~mL}$, was used for HPLC analysis. Each sample was injected 3 times and the mean was calculated.

\section{High pressure liquid chromatography}

HPLC (Shimadzu, Japan) chromatographic system consisted of a solvent delivery pump LC-10 AS, connected with an autoinjector model SIL-6A and a rheodyne injection valve fitted with a sample loop (20 $\mathrm{ml})$. A guard column filled with mBondapak $\mathrm{C}_{18}$ analytical waters mBondapak reversedphase column, effluents was monitored by using UV-detector (visible spectrophotometer detector SPD-10A). The output of the detector was connected to a chromatopack (CR6A). Mobile phase consisted of methanol (Merck HPLC grade) since Cypermethrin is miscible in alcohol. The methanol was purified by filteration through Millipore filtration unit (0.2 and $0.4 \mathrm{~mm}$ millipore filter, micropore, nylon). The filtered methanol was degassed prior to use by sonication. The flow rate was adjusted at $2 \mathrm{~mL} /$ min with total elution time of 10 min for each run. The column was flushed with deionized distilled water and methanol whenever required for removing impurities and was allowed to equilibrate between runs.

\section{RESULTS}

Isolation of pesticide degrading bacterial strain

During previous research study conducted by Hashmi (2000), two different colonies were observed on nutrient agar medium enriched with Malathion. One of the largest, most rapidly growing colonies of bacterial isolate was selected for detailed investigation. The ability of isolated organism (designated as IESPs-1) to degrade Cypermethrin was evaluated in this 
Table 1: Degradation of cypermethrin (40 mg/L) in the presence and absence of IES-Ps-1 culture using shaking water bath*

\begin{tabular}{lcccc}
\hline \multirow{2}{*}{$\begin{array}{c}\text { Time } \\
(\mathrm{H})\end{array}$} & $\mathrm{pH}$ & $\begin{array}{c}\text { COD } \\
\%\end{array}$ & \multicolumn{2}{c}{ HPLC data } \\
\cline { 3 - 5 } & & removal & $\begin{array}{c}\text { Cyper } \\
\text { Conc. } \\
(\mathrm{mg} / \mathrm{L})\end{array}$ & $\begin{array}{c}\text { Degradation } \\
\%\end{array}$ \\
\hline 0 & 7.2 & - & 44 & - \\
\hline 24 & 8.2 & 22 & 34 & 23 \\
\hline \multicolumn{5}{c}{ Without IES-Ps-1 culture } \\
\hline 24 & 7.8 & 10 & 41 & 6 \\
\hline *Data indicate average values of trplicates.
\end{tabular}

study. Cypermethrin was selected as it belongs to a group of bioresistant compounds which are not normally removed by conventional treatment plants.

Identification and characterization of bacterial isolate

On the basis of morphological, cultural and biochemical characteristics, the bacterial isolate was identified as a member of the genus Pseudomonas according to, Bergey's Manual of Determinative Bacteriology (1994). Characterization studies of the isolate from these experiments, as well as of those by other researchers, indicate that bacteria belonging to the genus pseudomonas are gram negative, rodshaped, highly oxidative and metabolically versatile, able to degrade aromatic hydrocarbons, oil, petroleum products and pesticides (Hashmi, 2000; Martin, et al., 2000; Ramanathan and Lalithakumari, 1999; Lee, et al., 1998; Ramos, et al., 1995; Maloney, et al., 1988).

Bacterial adaptation during the process of adaptation, it was observed that in the presence of high concentration of Cypermethrin, the bacteria was greatly stressed and its growth was slowed in consequence. The bacteria changed its normally rodshaped morphology to that of a coccus at increased insecticide concentration. However, this change was temporary, because the cells recovered the original rod form after a few days.

\section{Growth kinetic studies}

In the present study, a series of growth curve experiment was performed with specific dose of Cypermethrin to determine the viable count of pseudomonas (IES-Ps-1) and to verify whether they could be able to grow in the presence of added Cypermethrin. The optimum concentration of Cypermethrin that supports IES-Ps-1 growth was also evaluated. Results of the analysis are shown in Fig. 1.
Table 2: Comparative performance evaluation of Cypermethrin degradation at $48 \mathrm{~h}$ using biosimulator (activated sludge system)

\begin{tabular}{cccccc}
\hline $\begin{array}{c}\text { Cypermethrin } \\
\text { Conc. } \\
(\mathrm{mg} / \mathrm{L})\end{array}$ & $\mathrm{pH}$ & $\begin{array}{c}\text { COD } \\
(\mathrm{mg} / \mathrm{L})\end{array}$ & $\begin{array}{c}\text { Removal } \\
\%\end{array}$ & $\begin{array}{c}\text { Cyper Conc. } \\
(\mathrm{mg} / \mathrm{L})\end{array}$ & $\begin{array}{c}\text { HPLC data } \\
\text { degradation }\end{array}$ \\
\hline 20 & 8.6 & 85 & 87 & 0.5 & 98 \\
40 & 8.3 & 1080 & 82 & 8.0 & 80 \\
80 & 7.87 & 4500 & 54 & 42 & 51 \\
125 & 7.90 & 13760 & 24 & 112 & 22 \\
\hline
\end{tabular}

Growth kinetics of IES-Ps-1 in nutrient broth (control)

A control test without adding pesticide in nutrient broth was conducted in order to evaluate the mineralization potential of isolated strain when exposed to different concentration of Cypermethrin. It is seen from Fig. 1, that the phase of acclimation of Pseudomonas (IES-Ps-1) continued up to almost $4 \mathrm{~h}$., after the initial inocculation. The count at $0 \mathrm{~h}$. was $11 \times 10^{7}$ $\mathrm{CFU} / \mathrm{mL}$ and then started increasing slowly. At 6 h., the total viable count was $93 \times 10^{7} \mathrm{CFU} / \mathrm{mL}$ with generation time of $69 \mathrm{~min}$ and specific growth rate of 0.014 . At $24 \mathrm{~h}$. the total viable counts significantly increased (191x10 $\left.70^{7} \mathrm{CFU} / \mathrm{mL}\right)$, indicating that the culture after remaining in the lag phase (phase of adjustment) for $4 \mathrm{~h}$. entered into the phase of positive acceleration. The total viable count from $28 \times 10^{7} \mathrm{CFU} / \mathrm{mL}$ at $4 \mathrm{~h}$. significantly increased to $93 \times 10^{7} \mathrm{CFU} / \mathrm{mL}$ at $6 \mathrm{~h}$.and $197 \times 10^{7} \mathrm{CFU} / \mathrm{mL}$ at $24 \mathrm{~h}$. respectively showing that the culture entered the lag phase after $4 \mathrm{~h}$. and remain in that phase during 24 hours incubation.

\section{Growth kinetics of IES-Ps-1 in nutrient broth supplemented with Cypermethrin}

On comparing the growth of IES-Ps-1 in presence of Cypermethrin with that of control, it becomes clear from Fig. 1 that bacteria grows faster and a higher number of cells was observed when low dose of Cypermethrin was used. Since the aqueous solubility of Cypermethrin is very low $(0.01 \mathrm{mg} / \mathrm{L})$, these results are an indication of the difficulty that IES-Ps-1 has faced to grow in the presence of Cypermethrin. The growth of IES-Ps-1 in a medium supplemented with $40 \mathrm{mg} / \mathrm{L}$ and $60 \mathrm{mg} / \mathrm{L}$ Cypermethrin showing a marked increase in viable cell count at $24 \mathrm{~h}$. However, at high concentration of cypermethrin (80 mg/L and $125 \mathrm{mg} / \mathrm{L}$ ) the growth count significantly decreased with the 


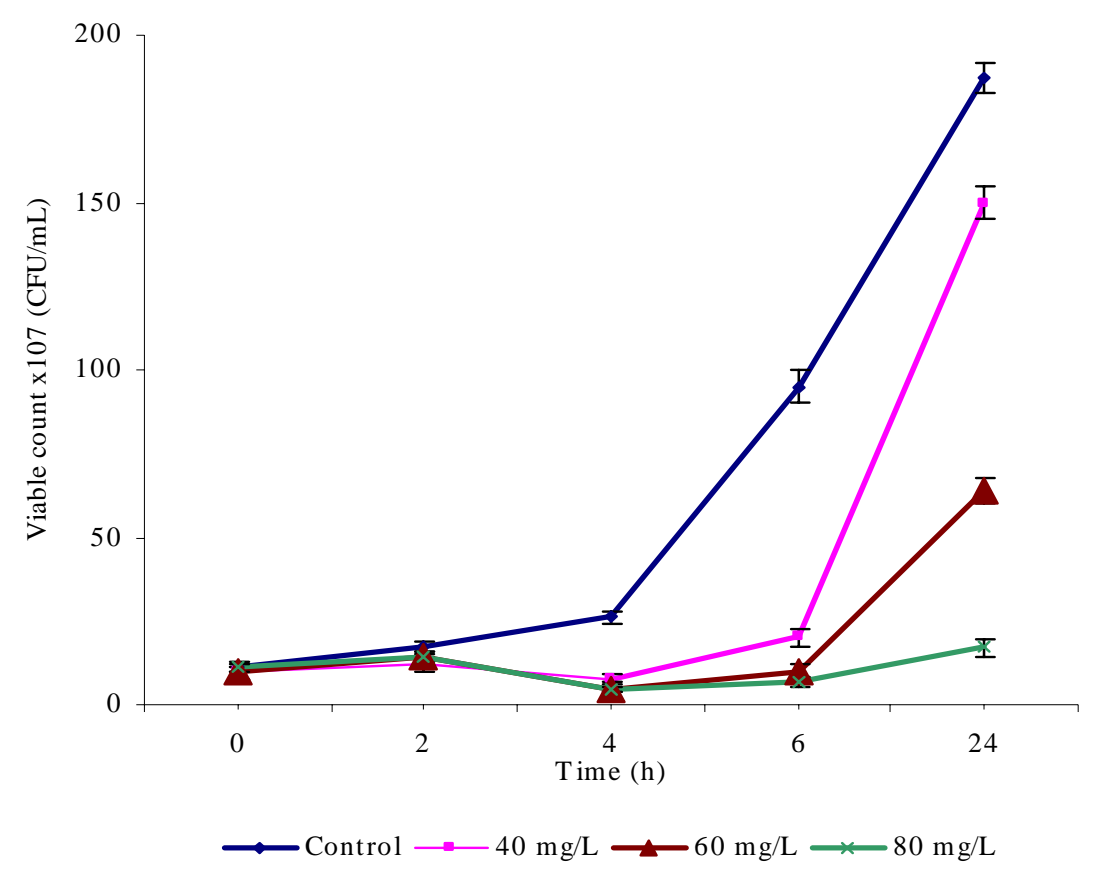

Fig. 1: Growth of IES-Ps-1 in the presence of Cypermethrin Error bars represents + SD from the average of trplicates. Error bars smaller than symbols are not depicted

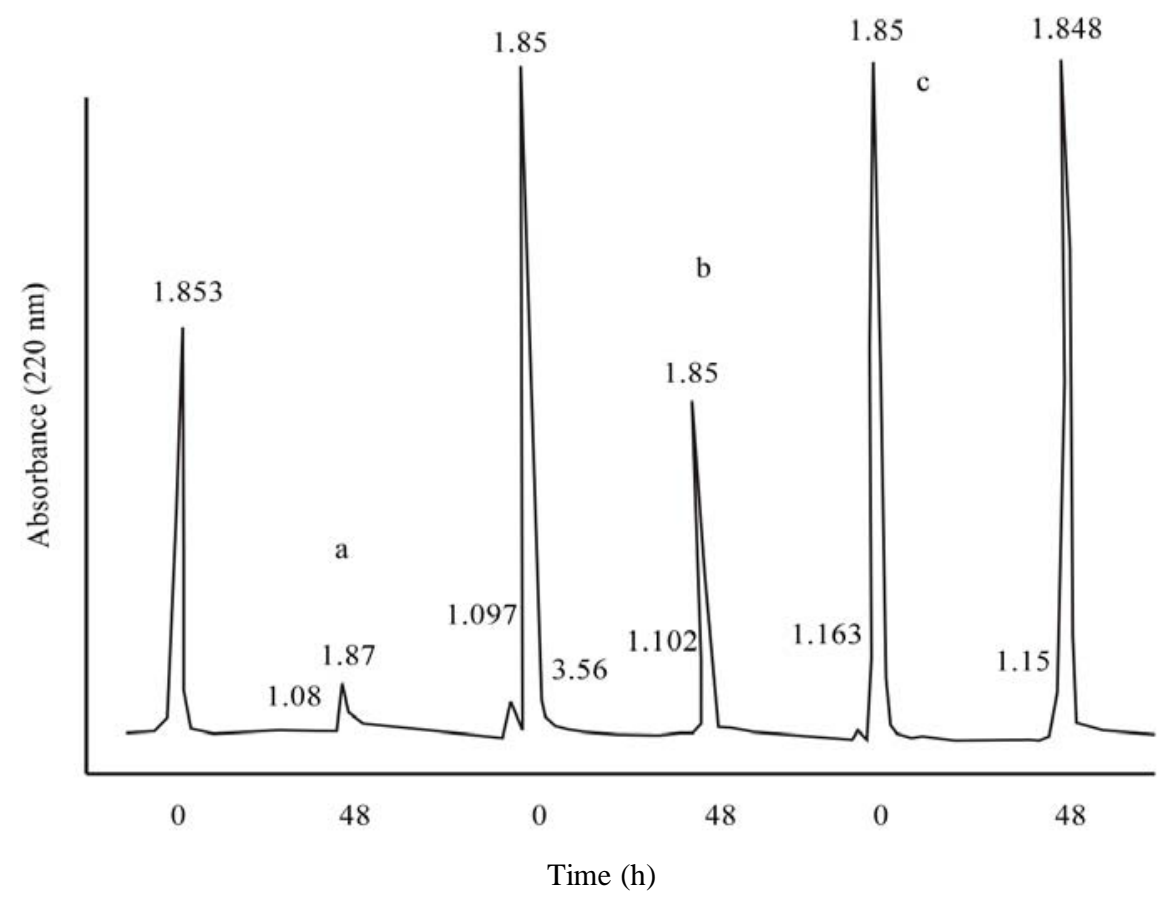

Fig. 2: HPLC chromatograms showing comparative effect of Cypermethrin concentration on biodegradation rates a: $40 \mathrm{mg} / \mathrm{L}$; b: $80 \mathrm{mg} / \mathrm{L}$; c: $125 \mathrm{mg} / \mathrm{L}$ 
increased in lag phase, but no inhibition in the growth was observed. At $6 \mathrm{~h}$. the viable count was noted to be $20 \times 10^{7} \mathrm{CFU} / \mathrm{ml}$ on using $40 \mathrm{mg} / \mathrm{L}$ Cypermethrin doses and $10 \times 10^{7} \mathrm{CFU} / \mathrm{mL}$ at $60 \mathrm{mg} / \mathrm{L}$ Cypermethrin concentrations. At 24 hours the total viable count at $40 \mathrm{mg} / \mathrm{L}$ and $60 \mathrm{mg} / \mathrm{L}$ became $150 \times 10^{7} \mathrm{CFU} / \mathrm{mL}$ and $64 \mathrm{x}$ $10^{7} \mathrm{CFU} / \mathrm{mL}$ respectively. The generation time with 40 $\mathrm{mg} / \mathrm{L}$ and $60 \mathrm{mg} / \mathrm{L}$ Cypermethrin doses was noted to be 88 and 113 minutes with specific growth rate of $0.011 \pm 1.0 \times 10^{-3} / \mathrm{min}$ and $0.0089 \pm 1.9 \times 10^{3} / \mathrm{min}$. However, at $80 \mathrm{mg} / \mathrm{L}$ and $125 \mathrm{mg} / \mathrm{L}$ Cypermethrin concentration, the generation time was calculated to be 185 and 212 minutes after inoculation with substrate utilization rate of $0.0052 \pm 8.3 \times 10^{-4} / \mathrm{min}$ and $0.0049 \pm 1.5 \times 10^{-3} / \mathrm{min}$. These observations suggest that the growth of IES-Ps-1 in the presence of Cypermethrin continued and proved that even high concentration Cypermethrin is not toxic to IES-Ps-1 strain, however, its mineralization potential decreased, which prolonged the lag phase.

\section{Biodegradation studies}

Biodegradation of Cypermethrin in wastewater using shaking water bath

Shaken culture experiments using acclimated cells of IES-Ps-1 with $40 \mathrm{mg} / \mathrm{L}$ Cypermethrin dose were initially carried out at ambient temperature (ranged from $18{ }^{\circ} \mathrm{C}-25^{\circ} \mathrm{C}$ ) in wastewater samples. Control tests with same concentration of Cypermethrin but no culture was run in parallel to determine the biodegradation potential of IES-Ps-1 in the presence of wastewater microorganisms. However, to relate the growth of organisms to the disappearance of Cypermethrin from wastewater samples, HPLC and COD analyses were carried out at fixed time intervals. Comparative performance evaluation of Cypermethrin degradation in the presence and absence of IES-Ps-1 are presented in Table 1.

Result shows that only about $23 \%$ degradation of Cypermethrin occurred after $24 \mathrm{~h}$. of aerobic incubation. On the other hand, in uninocculated control experiment negligible degradation was noticed. The COD removal seems proportional to the disappearance of Cypermethrin. The presence of high COD values coupled with low degradation is an indicative of the limit attainable with the biological treatment of wastewater using shaking water bath. However, in case of $\mathrm{pH}$ values no significant change in $\mathrm{pH}$ value was observed during biodegradation of Cypermethrin. The $\mathrm{pH}$ values remain towards alkaline side. This may be due to the self maintained buffer systems or due to the hydrolytic cleavage of organic matter present in wastewater sample (Hanel, 1988).

\section{Biodegradation of Cypermethrin in wastewater using biosimulator}

The potential of IES-Ps-1 strain for Cypermethrin degradation was also determined in a laboratory-scale activated sludge using biosimulator. Results of the analysis are recorded in Table 2 and shown in Fig.2.

\section{Influence of physicochemical conditions $p H$}

Results of the analysis indicate that Cypermethrin degradation by IES-Ps-1 in biosimulator continued satisfactorily even at alkaline $\mathrm{pH}(7.9$ - 8.3) and was found to degrade $20 \mathrm{mg} / \mathrm{L}$ to $40 \mathrm{mg} / \mathrm{L}$ Cypermethrin effectively. In contrast the degradation was reasonable at intermediate concentrations (80 mg/L Cypermethrin) and significantly lower results were obtained with concentrated samples having $125 \mathrm{mg} / \mathrm{L}$ Cypermethrin. During treatment, it was noted that biodegradation was not significantly affected because of the change in $\mathrm{pH}$ values from 7.9 to 8.3. As it is reported in literature that the tolerable limits for $\mathrm{pH}$ in activated sludge process is between 6.0 to 9.0 and even the influent $\mathrm{pH}$ values outside this range are of little or no practical significance (Hanel, 1988). Therefore, the similar results was also obtained in this study. Furthermore, according to literature, Cypermethrin hydrolyzes slowly in water at $\mathrm{pH} 7$ and below, with hydrolysis being more rapid at pH9 (Walker and Keith, 1992), therefore, the pHattained during treatment may have an additional advantage on Cypermethrin degradation.

\section{Dissoved oxygen}

It was observed during experiment that aeration system in the reactor not only provided oxygen but also kept Cypermethrin in suspension. Therefore, the COD removal and Cypermethrin degradation at ambient temperature using 8-9 mg/L DO was found to be significant at $20 \mathrm{mg} / \mathrm{L}$ to $40 \mathrm{mg} / \mathrm{L}$ concentration. However, at high concentration the degradation rate was markedly affected.

\section{Chemical oxygen demand}

During the experiment, a good correlation was established between COD removal and Cypermethrin degradation rates. It was observed that Cypermethrin 
concentration lowered from $40 \mathrm{mg} / \mathrm{L}$ to $8.0 \mathrm{mg} / \mathrm{L}$ ( $81 \%$ degradation) where as COD decreased from $6167 \mathrm{mg} / \mathrm{L}$ to $1080 \mathrm{mg} / \mathrm{L}$ (82 \% degradation). When the initial Cypermethrin concentration was $80 \mathrm{mg} / \mathrm{L}$, it was lowered to $42 \mathrm{mg} / \mathrm{L}$ (51 \% degradation) after $48 \mathrm{~h}$. aerobic treatment whereas COD diminished from $9767 \mathrm{mg} / \mathrm{L}$ to $4500 \mathrm{mg} / \mathrm{L}$ (54 \% degradation) in the same experiment. At higher concentration (125 mg/L), the initial Cypermethrin concentration recovery by HPLC analysis was greatly effected and was found to be more than the added concentration, and only $22 \%$ degradation was observed after 48 h.of aerobic treatment. Similarly $24 \%$ degradation was measured from COD values which further confirm the lower degradation rates.

\section{Influence of Cypermethrin concentration}

Different concentrations, ranging between 20 and 125 mg/L, were tested. Results as summarized in Table 2 indicate that due to mechanical aeration in the reactor Cypermethrin in the wastewater sample dispersed (mixed) and degradation at $40 \mathrm{mg} / \mathrm{L}$ was noted to be significantly high when compared with the results of shaken flask experiments. Further, as the culture IES-Ps-1 (Pseudomonas) is highly aerobic in nature, its degradation performance in bisimulator markedly improved due to sufficient availability of dissolved oxygen and $81 \%$ disappearance of Cypermethrin (40 $\mathrm{mg} / \mathrm{L}$ ) was observed after $48 \mathrm{~h}$ treatment. Over this period, the cells could utilize only $51 \%$ of Cypermethrin added initially at $80 \mathrm{mg} / \mathrm{L}$. Only $22 \%$ of this compound was degraded when it was given at $125 \mathrm{mg} / \mathrm{L}$, respectively in the samples. It was noted that at high concentration of Cypermethrin $(125 \mathrm{mg} / \mathrm{L})$, the initial recovery by HPLC analysis were found to be more than the added quantity. If considering the actual added amount, the removal rate at $125 \mathrm{mg} / \mathrm{L}$ was only $10 \%$. At this high concentration, the wastewater turn milky white and thus greatly reduced the biodegradation efficiency. During treatment it was noted that most of the biodegradation occur during 24 to $48 \mathrm{~h}$ (2-days) of aerobic treatment. However, after this time period biodegradation continue but at a slower rate, this may be due to low concentration of nutrients that remain in the wastewater sample (data not shown).

\section{DISCUSSIONAND CONCLUSION}

\section{Growth kinetic studies}

As growth kinetics provide an evidence of mineralization potential of organism therefore such studies were carried out by several researchers (Maria, et al., 2002; Karpouzas and Walker 2000; Lee, et al., 1998; Smith and Adkins 1995, Haugland, et al., 1990). In the present study, growth experiments conducted in the flask (without shaking) showed that IES-Ps-1 strain which was selected as a Malathion degrading microorganism is also able to grow in the presence of Cypermethrin. It was noted that after incubation at 35 ${ }^{\circ} \mathrm{C}$, the plating on nutrient agar medium from the solution of nutrient broth inoculated with IES-PS-1 and Cypermethrin showed a higher number of count at low concentration whereas at high concentration the number of organisms decreased or very slightly increased but no inhibition in the growth was observed when compared with the control tests (no pesticide). The plausible explanation may be that microorganisms need an acclimation period to induce the formation of necessary degradative enzymes. This may account for prolonged lag phase which was observed at high dose of added Cypermethrin. Another possibility of lower growth of IES-Ps-1 in the presence of Cypermethrin, may be the low availability of dissolved oxygen (DO), as experiment were conducted in the flask without shaking and it is also reported that increased organic load in the system usually cause a serious decrease in dissolved oxygen concentration (Corbitt, 1998). Based on the results from this study and that by Hashmi (2000) and other researchers it may be concluded that IES-Ps-1 strain is able to grow in the presence of added pesticide and therefore it could be effectively used for the treatment of pesticide contaminated soil or water. However, further research is necessary to understand the fundamental mechanism of enhancement and inhibition in microbial degradation at high concentration of pesticides.

\section{Biodegradation of Cypermethrin}

From experimental results conducted in shaking water bath, it can be assumed that lower degradation might be due to very low water solubility of Cypermethrin (Sapiets, et al., 1984). Due to low solubility, it might not be completely mixed in the wastewater sample and therefore metabolized by the IES-Ps- 1 culture. The assumption is also supported by Chaudhry (1994), who reported that biodegradation during treatment is greatly affected because of low solubility of compounds in an aqueous system, which was also observed in this study. In order to deal with this problem, experiments were then performed on large scale using biosimulator (Activated Sludge System), where Cypermethrin in wastewater sample was 
mixed continuously using mechanical agitation at a speed of $250 \mathrm{rpm}$. It was observed during experiment that mechanical agitation in the reactor not only provided the dispersion (mixing) of Cypermethrin in wastewater but also supplied sufficient oxygen in the reactor vessel.

Another possible explanation of low degradation of cypermethrin in shaking water bath would be the operational factors such as temperature and dissolved oxygen. As the experiment in shaking water was not performed under controlled temperature and dissolved oxygen, therefore this may also result in decreased rate of cypermethrin degradation. According to literature under normal environmental temperatures and $\mathrm{pH}$, cypermethrin is stable to hydrolysis with a half-life of $>50$ days (Walker and Keith, 1992). During experimental study conducted in biosimulator, IES-Ps-1 was found to retain their degradation ability at a wide range of $\mathrm{pH}$ $(\mathrm{pH}=7.2, \mathrm{pH}=8.5)$. However, increased concentration of cypermethrin (20-125 mg/L) gradually decreased the degradation performance of IES-Ps-1. Although, complete degradation at $20 \mathrm{mg} / \mathrm{L}$ cypermethrin wouldbe possible if appropriate organism (IES-Ps-1) and optimum operating conditions be maintained in biosimulator. It was noted that the removal of organic load in terms of COD was proportional to the disappearance of cypermethrin. Similar correlations were also observed by Berchtold, et al. (1995), who noticed the same correlation between COD removal and biodegradation of 2,4-DAT and also 2,4 and 2,6 diamino toluene degradation by acclimated bacteria (Pesce and Wunderlin, 1997). In biosimulator, due to mechanical aeration in the reactor, cypermethrin degradation at $40 \mathrm{mg} / \mathrm{L}$ was noted to be significantly high when compared with the results of shaken flask experiments where the observed degradation was only 23\% after 24 hours incubation. This suggest that as the culture IES-Ps-1 (Pseudomonas) is highly aerobic in nature, its degradation performance in bisimulator markedly improved. However, at increased concentration of cypermethrin, from $40 \mathrm{mg} / \mathrm{L}$ to $125 \mathrm{mg} / \mathrm{L}$, a marked negative effect on the rate of degradation was observed. Several researchers also reported similar results of lower degradation at high concentration of hazardous organic compounds (Ashok and Seth, 1989; Smith and Adkins, 1995; Collins and Daugulis, 1996; Silvia and Wunderlin, 1997; Lee, et al., 1998; Goudar and Strevett, 2000). It was also noted during experimental analysis that due to low water solubility of cypermethrin, the wastewater turned milky white and therefore greatly reduced the biodegradation efficiency. Further, most of the biodegradation was found during 24 to 48 h. (2-days) of aerobic treatment when the bacterial cells were in the log phase. However, after this time period biodegradation continued but at a slower rate (72 and $96 \mathrm{~h}$. data are not shown in Table). This may be due to mineral nutrients which is required for the growth of IES-Ps-1 and biodegradation of cypermethrin may become rate limiting in the wastewater sample after $48 \mathrm{~h}$. (e.g phosphorus is frequently limiting in surface waters, Lewis, et al., 1986). The present research findings described that this may be the first instance in which high concentration of cypermethrin degradation has been achieved in short retention time of $48 \mathrm{~h}$. Although Maloney et al., (1988), reported the transformation of permethrin $(50 \mathrm{mg} / \mathrm{L})$ by pure culture of Pseudomonas fluorescence in the presence of tween 80 under aerobic conditions with a half-life of less than 5 days. Grant, et al., (2002), reported that technical grade cypermethrin can be reduced from $60 \mathrm{mg} / \mathrm{L}$ to $6 \mathrm{mg} / \mathrm{L}$ by Pseudomonas sp. in 20 days. The over all findings suggest that biosimulator used as activated sludge for the degradation of cypermethrin by IES-Ps-1 culture may be feasible and a reasonable treatment option for the removal of pesticide wastes from wastewater as biodegradation observed only in the presence of acclimated microorganism as well as under aerobic conditions using mechanical aeration system.

\section{ACKNOWLEDGMENTS}

The authors greatly acknowledge the partial financial support of NDP to carry out this research study.

\section{REFERENCES}

APHA. (1992). Standard methods for examination of water and wastewater, $18^{\text {th }}$ edi., American Public Health Association, Washington, D.C.

Arnol, S. M., Hickey, W. J., (1995). Degradation of atrazine by Fenton's reagent: Condition optimization and product quantification. Environ. Sci. Technol., 29, 2083-2089.

Babcock, R. W., Jr, K. S., Ro, C. C., Hsick, Stenstorm, M. K., (1992). Development of an offline enricher-reactor process for activated sludge degradation of hazardous waste. Water Environ. Res., 64, 782-791.

Berchtold, S. R., Vanderloop, S. L., Suidan, M. T., Maloney, S. W., (1995). Treatment of 2,4-diaminotoluene using a two stage system: fluidized-bed anaerobic granular activated carbon reactor. Wat. Environ. Res., 67, 1081-1091.

Bergey's Manual of Determinative Bacteriology, (1994). Edited by

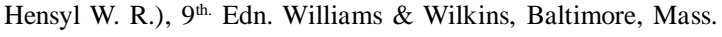


Chaudhry, G. R., (1994). Biological degradation and bioremediation of toxic chemicals. Dioscorides Press, Portland, OR. USA.

Collins, C. H. and Lyne, P. M., (1985). Microbiological Methods. $5^{\text {th. }}$ Edition. Butterworth and Co (Publishers) Ltd.

Dagley, S. (1986). Biochemistry of aromatic hydrocarbons degradation in Pseudomonads. In: The Bacteria. Vol.10. Edited by J. R. Sokatch. Academic Press. New York: 527.

Dolfing, J., Zeyer, J., Binder-Eicher, P., Schwarzenback and R. P., (1990). Isolation and charaterization of a bacterium that mineralizes toluene in the absence of molecular oxygen. Arch Microbiol., 154 (4):336-341

Goudar, C. T. and Strevett, K. A., (2000). Substrate inhibition kinetics of phenol biodegradation. Wat. Env. Res,. 72, 5055.

Grady, C. P. L., (1986). Biodegradation of hazardous waste by conventional biological treatments. Haz. Wastes Haz. Mater., 3, 333-365.

Grant, R. J., Daninell, T. J. and Betts, W. B., (2002). Isolation and identification of synthetic pyrethroid-degrading bacteria. J. Appl. Microbiol., 92 (3), 534-540.

Hanel, K., (1988). Biological treatment of sewage by the activated sludge process. Ellis Horwood Publisher, John Wiley and Sons. New York, USA.

Hashmi, I., (2000). Microbiological transformation of hazardous waste during biological treatment. Ph.D. Thesis. Institute of Environmental Studies, University of Karachi. Pakistan.

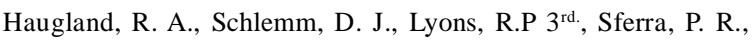
Chakarbarty, A. M., (1990). Degradation of the chlorinated phenoxy acetate herbicide-2,4-dichlorophenoxy acetic acid and 2,4,5-trichlorophenoxy acetic acid by pure and mixed cultures. Appl. Environ Microbiol., 56 (5), 1357-1362.

Huston, L. P., Pignatello, J. J., (1999). Degradation of selected pesticide active ingredients and commercial formulation in water by the photo assisted fenton reaction. J. Water Res. 33 (5), 1238-1246.

Karpouzas, D. G., Morgan, J. A., Walker, A., (2000). Isolation and characterization of 23 carbo-furan-degrading from soils from distant geographical areas. Lett. Appl. Microbiol., 31 (5), 353-8.

Kumaran, P., Shivaraman, N., (1988). Biological treatment of toxic industrial wastes. In: Biotreatment systems, D. L. Wise Ed. CRC Press, Boca Raton, FL. 1, 227-283.

Lal, R., Lal, S., Dhanraj, P. S., Saxena, D. M., (1995). Manipulation of catabolic genes for the degradation and detoxification of xenobiotics. Adv. Appl. Microbiol., 41, 55-95.

Lee, S. G., Yoon, B. D., Park, Y. H., Oh, H. M., (1998). Isolation of a novel pentacholorophenol-degrading bacterium, Pseudomonas sp. Bu 34. J. Appl. Microbiol., 85, 1-8.

Lewis, D. L., Kollig, H. P. and Hodson, R. E., (1986). Nutrient limitation and adaptation of microbial population to chemical transformations. Appl. Environ. Microbiol., 51, 598-603.

Maloney, S. E., Maule, A., Smith, A. R. W., (1988). Microbial transformation of the pyrethroid insecticides: Permethrin, Deltamethrin, Fastac, Fenvalerate and Fluvalinate. Applied and Environment Microbiology. 2874-2876.
Mangat, S. S., (1999). Biodegradation of the herbicide 2,4dichlorophenoxy-acetic acid (2,4-D) in sequencing batch reactors. Water Res., 33 (3):861-867.

Maria, K., Graciela, C., Zauscher, F., (2002). Biodegradation of two commercial herbicides (Gramoxone and Matancha) by the bacteria Pseudomonas putida. EJB J. Env. Biotech., 5 (2).

Martin, M., Mengs, G., Plaza, E., Garbi, C., Sanchez, M., Gibello, A., Gutierrez, F., Ferrer, E., (2000). Propachlor removal by Pseudomonas strain GCH 1 in an immobilized cell system. Appl Environ Microbiol., 66 (3), 1190-1194.

Pesc, S. F. and Wunderlin, D. A., (1997). Biodegradation of 2,4- and 2,6-diaminotoluene by acclimated bacteria. Water Res., 31 (7), 1601-1608.

Ramanathan, M. P. and Lalithakumari, D., (1999). Complete mineralization of methylparathion by Pseudomonas sp. A3. Appl. Biotechnol., 80 (1), 1-12.

Ramos, T. L., Duque, E., Huertas, M. J., Haidour, A., (1995). Isolation and expansion of the catabolic potential of a Pseudomonas putida strain able to grow in the presence of high concentration of aromatic hydrocarbons. J. Bacteriol., 177, 3911-916.

Rani, N. L. and Lalitha Kumari, D., (1994). Degradation of methyl parathion by Pseudomonas putida. Can. J. Microbiol., 40 (12), 1000-6.

Roy, D., Monstafa, H., Maillacheruvu, K., (1997). Analine degradation in a soil slurry bioreactor. J. Environ. Sci. Health., 32 (8), 2367-2377.

Rozkov A., Vassiljeva, I., Kurvet, M., Kahru, A., Preis, S., Kharchenko, A., Kricheuskayam, M., Liiv, M., Kaard, A., Vilu, R., (1999). Laboratory study of bioremediation of rocket fuel-polluted ground water. Water Res., 33 (5): 13031313.

Safe, S. H., (1984). Microbial degradation of polychlorinatedbiphenyls, In: Microbial degradation of organic compounds, Gibson. D. T. Ed., Marcel Dekker, New York. 361.

Sapiets, A., Swaine, H., Tandy, M. J., (1984). Cypermethrin. In: Analytical methods for pesticides and plants growth regulators. Zweig G., Sherma J. (Eds). Academic Press, New York, XIII, 33.

Sayler, G. S. and Blackburn, J. W., (1989). Modern biological methods: The role of biotechnology. In: Biotreatment of agricultural wastewater, ME Huntley, Ed.CRC Press, Boca Raton, FL. 53-71.

Sisodia, S. S., Weber, A. S., Jensen, J. N., (1996). Continuous culture biodegradation of simazine's chemical oxidation products., Water Res., 30 (9), 2055-2064.

Smith-Greeier, L. L. and Adkins, A., (1996). Isolation and Characterization of soil microorganisms capable of utilizing the herbicide dichloro-p-methyl as a sole source of carbon ans energy. Can J. Microbiol., 42 (2), 221-226.

Somich, C. J., Maldoon, M. T., Kearney, P. C., (1990). On-site treatment of pesticide waste and rinsate using ozone and biologically active soil. Environ Sci. Technol., 24, 745749 .

Straube, G., (1991). Microbial transformation of hexachlorocyclohexane. Zentralbl Mikrobiol., 146 (5), 327338. 
Sudo, M., Kunimatsu, T., Okubo, T., (2002). Concentration and loading of pesticide residue in lake Biwa basin (Japan). Water Res., 36 (4), 315-329.

Tartakouvsky, B., Michotte, A., Cadieu, A., Lau, P. C. K., Hawari, J., Guiot, S. R., (2001). Degradation of aroclor 1242 in a single stage coupled anaerobic bioreactor. Water Res., 35 (18), 4323-4330.

US EPA. (1992). Pesticide Fact Sheet Database, Washington, D.C.
Yu, J. J., (2002). Removal of organophosphate pesticides from wastewater by supercritical carbon dioxide extraction. Water Res., 36 (4), 1095-1101.

Zacharias, B., Lang, E., Hanert, H. H., (1995). Biodegradation of chlorinated aromatic hydro-carbons in slowsand filters simulating conditions in contaminated soil-Pilot study for in situ cleaning of an industrial site., Water Res., 29 (7), 1663-1671.

\section{AUTHOR(S) BIOSKETCHES}

Jilani, S., M.Sc, M.E, Ph.D., (Environmental Science) is a assistant professor in the Department of Environmental Engineering, NED University of Engineering \& Technology, Karachi, Pakistan.

Email: seemajilani2000@yahoo.com

Altaf Khan, M., M.Sc, Ph.D., (Microbiology) is a former Director \& Professor at Institute of Environmental Studies, University of Karachi, Karachi, Pakistan. Presently working as retired Professor at the same institute.

Email:altafkhan10@hotmail.com

\section{This article should be referenced as follows:}

Jilani, S. and Altaf Khan, M., (2006). Biodegradation of cypermethrin by pseudomonas in a batch activated sludge process. Int. J. Environ. Sci. Tech., 3 (4), 371-380 